ORIGINAL ARTICLE

PRACA ORYGINALNA

\title{
THE EXPERIENCE OF SURGICAL TREATMENT OF THE PATIENTS WITH EXTENDED CICATRICIAL ESOPHAGEAL STRICTURES
}

DOI: 10.36740/WLek202002104

\author{
Valeriy V. Boyko ${ }^{1,2}$, Serhii 0. Savvi ${ }^{1,2}$, Alla Yu. Korolevska ${ }^{1,2}$, Serhii Yu. Bytyak ${ }^{1,2}$, Vitalii V. Zhydetskyi", \\ Yevhen A. Novikov ${ }^{3}$, Robert 0. Surmanidze ${ }^{1}$ \\ 'KHARKIV NATIONAL MEDICAL UNIVERSITY, KHARKIV, UKRAINE \\ ¿STATE INSTITUTION "ZAITSEV V. T. INSTITUTE OF GENERAL AND URGENT SURGERY OF NATIONAL ACADEMY OF MEDICAL SCIENCES OF UKRAINE", \\ KHARKIV, UKRAINE \\ 3KARAZIN V. N. KHARKIV NATIONAL UNIVERSITY, KHARKIV, UKRAINE
}

\begin{abstract}
The aim of the researce was the improvement of treatment results of patients with extended post-burn esophageal cicatricial strictures.

Materials and methods: The treatment results are presented for 102 patients which were divided into two groups. In 49 patients with extended post-burn esophageal cicatricial strictures of the main group modified esophagoplasty were performed. Traditional esophagoplasty in 53 patients of the comparison group was performed.

Results: A trend was observed on reduction in both short-term and long-term post-operative complications and lethality. The comparative analysis showed statistically valid reduction in number of complications caused by radical surgery: in the main group the frequency of short-term post-operative complications was $10,2 \%$, in the comparison group $-45,3 \%$, the frequency of long-term post-operative complications being in the main group $8,2 \%$, and in the comparison group $26,4 \%$. A trend was observed on reduction of both local and general complications, which may be explained by both peculiarities of the operative interventions with application of improved surgical treatment methods and by more efficient pre-operation preparation of the patients. Post-operative lethality level was 2,0\% in the main group, and 3,8\% in the comparison group. Life quality parameters in the main group patients in the long-term post-operation period were statistically significantly better.

Conclusions: In patients with extended post-burn esophageal cicatricial stricture application of the proposed surgical tactics, modified method of single-step esophagoplasty and esophagoplasty as Step II of the surgical treatment for persons who have a formed contact gastrostomy is an efficient means for patients' treatment improvement.
\end{abstract}

KEY WORDS: extended post-burn cicatricial esophageal strictures, transchiatal esophagoplasty, gastrostomy, antireflux anastomosis, stoma on the neck

Wiad Lek. 2020;73(2):229-234

\section{INTRODUCTION}

Treatment of patients with extended post-burn esophageal cicatricial strictures is an unsolved problem as per now, requiring further deeper study in order to improve the treatment results and life quality of the patients $[1,2,3,4]$. First of all, this is due to the large amount of patients with this pathology and complicated, time-consuming treatment as well as to the necessity of frequent reconstructive reparative surgical interventions that cannot exclude the disability of the patients. That is why the treatment tactics of such patients has remained complicated and contradictory up to this day $[5,6]$.

Esophagoplasty based on esophageal anastomosis formation is up to now criticized for high percentage of complications, though the amount of complications has lately reduced. The main reason of post-surgery lethality after esophagoplasty is leakage of esophageal anastomosis $[7,8]$.

Appearance of esophageal anastomosis stricture (its frequency different authors estimate as 9 to $30 \%$ ) indicates a surgical treatment failure, as the patient with esophagus stenosis expects to restore adequate food permeability after surgery and, accordingly, adequate feeding, whereas esophageal anastomosis stricture deprives the patient of this ability [9].

A number of post-surgery problems remains insufficiently studied, such as dumping syndrome, esophagus-respiratory reflux and its consequences and dysphagy in patients after esophagoplasty. Thus, the questions of post-surgery complication prophylaxis are drastically urgent and require further deeper study.

\section{THE AIM}

The aim of the researce was the improvement of treatment results of patients with extended post-burn esophageal cicatricial strictures.

\section{MATERIALS AND METHODS}

The research is based on the results of treatment of 102 patients with extended post-burn esophageal cicatricial strictures at the Department of the Diseases of the Esophagus and Gastrointestinal Tract, State Institution "Zaitsev V. T. Institute of General and Urgent Surgery of National 
Academy of Medical Sciences of Ukraine", within the period 2000 to 2018 . Two groups of patients were formed in the course of research depending on the type of performed reconstructive reparative surgical interventions. In the main group of 49 persons esophagoplasty was made according to newly developed modified methods. The comparison group of 53 persons was formed according to the data of case report retrospective study. They received esophagoplasty under traditional methods. Both groups were identical as regards the main factors at the initial stage of studies, the significance level being $\mathrm{p}<0,05$. The main group included 46 males $(93,9 \%)$ and 3 females $(6,15)$ at the average age of $44,4 \pm 5,3$ years. In the comparison group there were 49 males $(92,5 \%)$ and 4 females $(7,5 \%)$ at the average age of $43,0 \pm 5,1$ years. Both groups consisted of employable age people (18 to 59 years).

All patients were addmitted to hospital with formed esophagus strictures. In the main group $25(51,0 \%)$ patients had extended esophageal strictures which occupied more than 2 anatomic divisions of esophagus and the rest 24 (49,0\%) patients had extended esophageal strictures which occupied 2 anatomic divisions of esophagus, whereas in the comparison group $27(50,9 \%)$ and $26(49,1 \%)$ respectively. Most patients of both groups also had concomitant pathologies, except $2(4,1 \%)$ in the main group and $3(5,7 \%)$ in the comparison group. More than one third of patients in both groups were alcoholics.

When patients were hospitalized, they underwent comprehensive clinical laboratory tests and instrumental examinations. X-ray examinations were performed at the equipment TUR-1101. For ultrasonic diagnostics (USD) of thoracic, abdominal and pleural cavities we applied Siemens Sonoline G-50, as well as Toshiba Aplio XG ultrasonic system. Computer tomography was performed at Toshiba Astenion. For endoscopic examination Fujinon W series videoendoscopic system served as well as WG-88FP videoendoscope for the upper gastrointestinal tract. Additionally at late post-surgery period basic express $\mathrm{pH}$-metry was performed under visual control in the course of the upper gastrointestinal tract endoscopy using IGS-2 gastric acidity indicator and the upper gastrointestinal tract $\mathrm{pH}-\mathrm{Z}$-impedance monitoring using equipment for $\mathrm{pH}-\mathrm{Z}$-impedancemonitoring.

The results data array was processed using variation statistics methods. To definite the uniformity between the groups under study we applied Pearson fitting criterion $\left(\chi^{2}\right)$ at $p<0,05$. Statistical confidence of the difference between the average values of the main group and the comparison group parameters was evaluated with the help of Student $\mathrm{t}$-criterion (for numerical data) and non-parametric Mann-Whitney U-test (for non-numerical scales). The difference was treated as confidential at the statistical significance $p<0,05$. Statistical processing of data was performed at ASUS T100 PC using Stat Plus 2009 Professional 5.8.4 as well as Microsoft Excel 2010 software.

\section{RESULTS AND DISCUSSION}

To patients of the main group with extended post-burn esophageal cicatricial strictures on a par with the traditional methods some new dilatation procedure methods were applied as developed in the course of research: esophagus stricture forced vibration bougienage (Ukrainian patent № 93529 of 10.10 .2014 ) was applied to 12 persons; method and apparatus for vibration bougienage of extended strictures with complicated anatomic pattern (Ukrainian patent № 93560 of 10.10.2014) was applied to 15 persons; method of esophagus stricture dilatation in patients with gastrostomy (Ukrainian patent № 103408 of 10.12.2015) was applied to 13 persons. Any complications in the course and after the above dilatation procedures were never observed. X-ray control examination of the upper gastrointestinal tract confirmed the positive dynamics in esophageal lumen expansion and positive changes in stricture architectonics. These patients showed longer remission periods between the dilatation procedure courses as compared to the existing methods. It is an evidence of higher efficiency of the proposed dilatation procedures.

Due to consideration of the severity of clinical course of this sickness, total condition of the patients, expression of nutritive status insufficiency, we improved and implemented the treatment tactics for patients with formed extended post-burn esophageal cicatricial strictures based on the efficiency of the dilatation procedure courses mandatory for all patients under impaired nutritive status disorders due to dysphagy.

The final aim of such patients treatment was the restoration of natural food passage. If stable positive effect is reached by the repetitive dilatation procedure courses, the patients are not liable to surgery. In most cases with esophageal permeability being restored by the dilatation procedure courses only for a certain period of time, after which the patients with rigid esophageal strictures required the repetitive courses of bougienage or balloon dilatation, their life quality deteriorated. When the dilatation procedure was impossible, or its effect was too short-lived, or was not reached at all, surgical treatment might become necessary. To determine the type and scope of surgical intervention it was feasible to evaluate the general condition of patient with extended post-burn esophageal cicatricial strictures, his nutritive status, presence or absence of concomitant pathologies and complications, efficiency of the previous dilatation procedure courses. When the dilatation procedure courses were inefficient or it was impossible to perform them in patients with dysphagy stage III-IV, emaciation developed with expressed metabolic disorders, and sometimes even cachexia. Such patients were liable to two-step surgical treatment. At Step 1 a contact gastrostomy was formed to ensure enteral feeding and improve nutritive status. After gastrostomy formation the patients were subdued to dilatation procedure courses. In the case of the efficient outcome after those procedures the patients with extended post-burn esophageal cicatricial strictures, with the restored esophageal lumen and dysphagy stage 1, were hospitalized to close contact gastrostomy after a medical check-up. In the case of the dilatation procedures inefficiency as Step 2 of the surgical treatment after the nutritive status restoration, esophageal resection, esophagoplasty, and closure of gastrostomy opening were performed. 


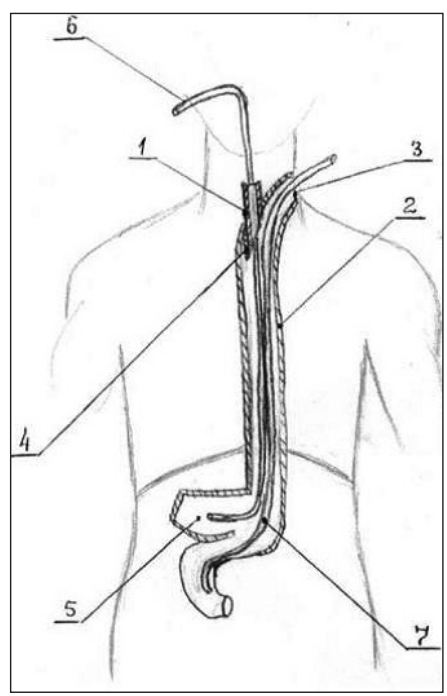

Fig. 1. Overview of the upper gastrointestinal tract after the completion of esophagogastroplasty: (1 - esophageal stump, 2 - gastric interponate displaced to esophagus position, 3 - stoma on the neck, 4 - newly formed valve in esophagogastrostomosis area on the neck, 5 - gastric reservoir, 6 - nasogastric tube, 7 - patient alimentation tube).

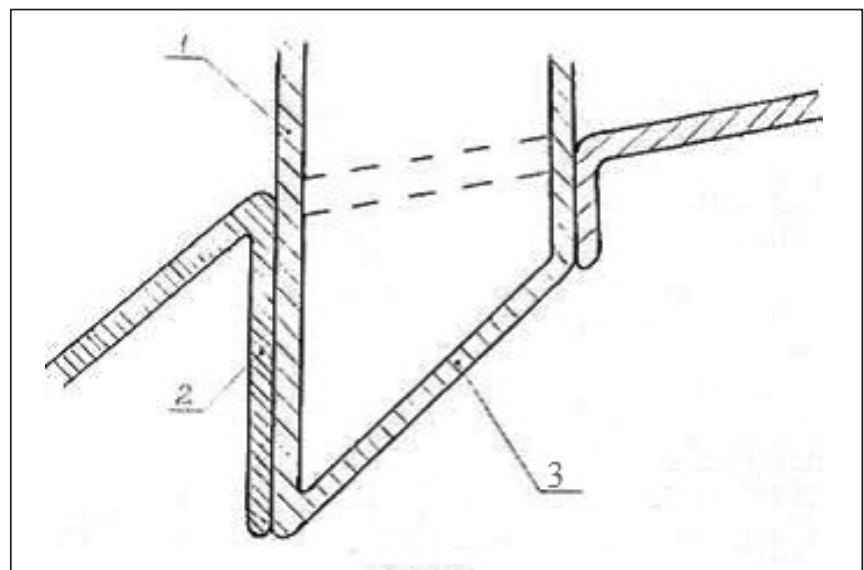

Fig. 3. Valve in quiet condition: (1 - esophageal stump, 2 - gastric interponate, 3 - newly formed valve).

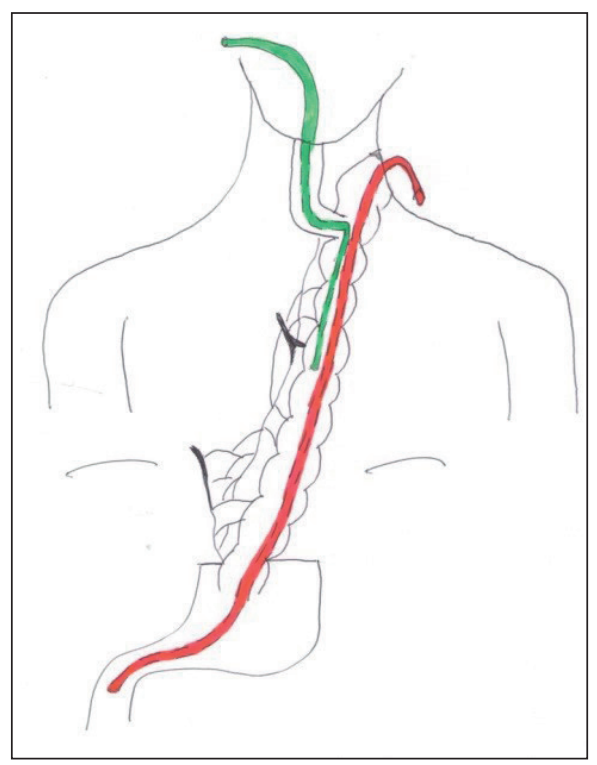

Fig. 5. Double tubing.

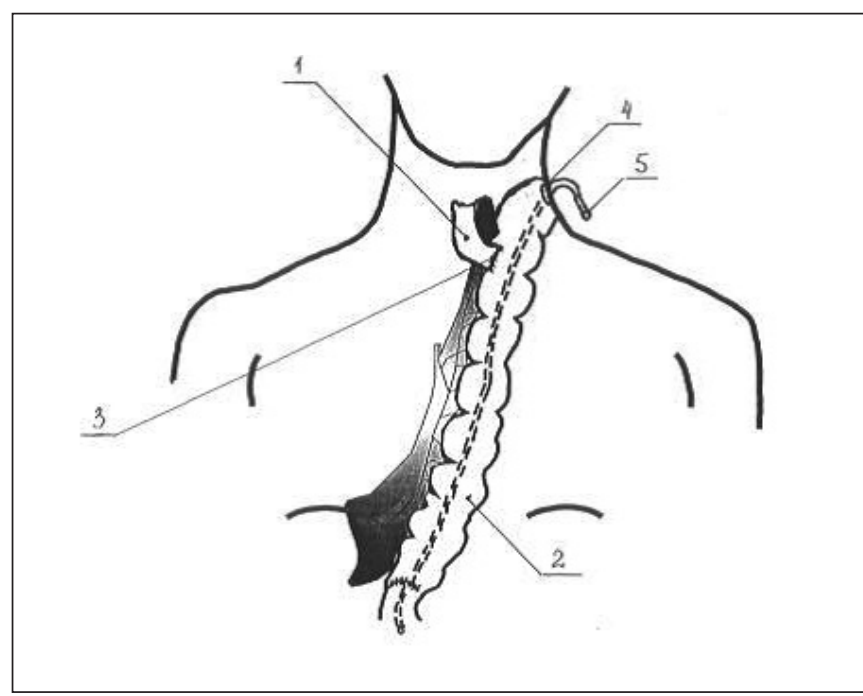

Fig. 2. Modified esophagocoloplasty: (1 - esophageal stump, 2 - large intestinal interponate, 3 - „end-to-side” anastomosis between esophagus and interponate, 4 - patient's neck stoma, 5 - tube).



Fig. 4. Valve at the moment of its closure under the action of interponate content retrograde movement: (1 - esophageal stump, 2 - gastric interponate, 3 - newly formed valve).

If cachexia and severe concomitant pathology were absent in a patient with extended post-burn esophageal cicatricial strictures, after inefficient bougienage or dilatation courses the patient was proposed reconstructive reparative surgical intervention and after the patient's consent and pre-surgery preparation on the elective basis, the patient underwent single-step esophagoplasty. The above-described tactics enables the attainment of final aim of treatment in all cases.

The main group patients underwent the modified transhiatal resection of the cicatrically-changed esophagus with esophagoplasty, the antireflux cervical esophageal anastomosis formation and exteriorization of the interponate distal end as a contact stoma on the neck. 39 patients had esophagoplasty performed by the gastric interponate formed as an isoperistaltic tube along the greater curvature of the stomach (Fig.1). 
Table 1. Early postoperative complications in extended post-burn esophageal cicatricial stricture patients after esophagoplasty

\begin{tabular}{|c|c|c|c|c|}
\hline \multirow[t]{2}{*}{ Complications } & \multicolumn{2}{|c|}{$\begin{array}{l}\text { Main group } \\
\mathrm{n}=49 \text { patients }\end{array}$} & \multicolumn{2}{|c|}{$\begin{array}{c}\text { Comparison group } \\
n=53 \text { patients }\end{array}$} \\
\hline & $\mathbf{n}$ & $\%$ & $\mathbf{n}$ & $\%$ \\
\hline Pleurisy & 3 & 6,2 & 8 & 15,1 \\
\hline Pneumonia & - & - & 2 & 3,8 \\
\hline Mediastinitis & - & - & 3 & 5,6 \\
\hline Partial leakage of cervical esophageal anastomosis & 1 & 2,0 & 3 & 5,6 \\
\hline Total leakage of cervical esophageal anastomosis & - & - & 2 & 3,8 \\
\hline Partial leakage of thoracic esophageal anastomosis & - & - & 1 & 1,9 \\
\hline Partial leakage of intraabdominal colo-coloanastomosis & - & - & 1 & 1,9 \\
\hline Acute cardiovascular failure & 1 & 2,0 & 1 & 1,9 \\
\hline Multiple organ failure & - & - & 3 & 5,7 \\
\hline Total & 5 & 10,2 & 24 & 45,3 \\
\hline
\end{tabular}

Table 2. Long-term postoperative complications in extended post-burn esophageal cicatricial stricture patients after esophagoplasty

\begin{tabular}{|c|c|c|c|c|}
\hline \multirow[t]{2}{*}{ Complications } & \multicolumn{2}{|c|}{$\begin{array}{l}\text { Main group } \\
\mathrm{n}=49 \text { patients }\end{array}$} & \multicolumn{2}{|c|}{$\begin{array}{c}\text { Comparison group } \\
n=53 \text { patients }\end{array}$} \\
\hline & $\mathbf{n}$ & $\%$ & $\mathbf{n}$ & $\%$ \\
\hline Dysphagy & - & - & 3 & 5,7 \\
\hline Reflux esophagitis at the esophageal stump & 1 & 2,0 & 3 & 5,7 \\
\hline Gastrointestinal reflux & 1 & 2,0 & 3 & 5,6 \\
\hline Interponate elongation & - & - & 1 & 1,9 \\
\hline Esophageal anastomosis cicatricial stenosis & 1 & 2,1 & 3 & 5,6 \\
\hline Acute cardiovascular failure & - & - & 1 & 1,9 \\
\hline Cerebral arteries thrombosis with cerebral infarction & 1 & 2,1 & - & - \\
\hline Total & 4 & 8,2 & 14 & 26,4 \\
\hline
\end{tabular}

10 patients of the main group underwent modified esophagocoloplasty as the gastric interponate application was impossible: 5 of them suffered from the pylorus stenosis due to burn (an additional step in the course of esophagoplasty was gastroenteroanastomosis formation), whereas other 5 patients had surgical interventions on the stomach in anamnesis vitae (Fig.2).

The method of anastomosis application between the esophageal stump and gastric interponate enabled to ensure the valve strength at the account of steady (double-row) stitches as well as of its thickness (united thicknesses of the esophageal wall and interponate tissues) (Figs.3, 4).

Antireflux anastomosis "end-to-side" (between the esophageal end to interponate side) enables usage of the interponate proximal part above the anastomosis level as a free end of "esophageal pipe" to stoma exteriorization and tube inserting. The first tube is brought transnasally behind the antireflux anastomosis area for decompression and the second tube is brought for enteral feeding to the duodenum via a contact stoma on the neck (Fig.5).

In the comparison group, 53 patients with extended postburn esophageal cicatricial strictures underwent esophago- plasty by traditional methods: 6 patients underwent a distal resection of the cicatricially-changed esophagus with Lewis esophagogastroplasty, 20 patients underwent a single-step esophagocoloplasty, whereas all 27 patients with contact gastrostomy underwent traditional esophagocoloplasty as Step II of the surgical treatment.

The study of acidity pattern by basal express $\mathrm{pH}$-metry with visual control of the upper gastrointestinal tract in patients after $3,6,9,12$ months of surgery showed that after esophagoplasty all patients had reflux from the interponate into the esophageal stump. Reflux in the comparison group patients was longer and more intensive than in the main group patients.

In all patients of the main group, the DeMeester score was below 14,72, which indicates the absence of pathological reflux. In all patients of the comparison group DeMeester score was greater 14,72, which indicates pathological reflux.

In all patients of the comparison group, the voluminous and chemical clearance in the esophageal stump was disturbed due to motor evacuation disorders.

In patients of the main group, the physiological character of reflux was confirmed due to the presence of the antireflux barrier. 
In $44(89,8 \%)$ patients of the main group and $29(54,7 \%)$ patients of the comparison group, the post-surgery period was successful. The analysis of the early treatment results of the patients with extended post-burn esophageal cicatricial strictures after esophagoplasty showed more favorable postoperative course in the main group patients as distinct from the comparison group patients: transnasal tube was maintained 11,7 days less, early activation of the patients took place 3,4 days earlier, parenteral feeding lasted 5,1 days less in the comparison group, enteral feeding began 4,2 days earlier.

Early postoperative complications were observed in 5 $(10,2 \%)$ main group patients and $24(45,3 \%)$ comparison group patients (Table 1).

The leakage of cervical esophageal anastomosis was diagnosed in $6(5,9 \%)$ operated patients. The partial leakage of cervical esophageal anastomosis was diagnosed in 1 (2\%) main group patient. The tube brought in the course of operation through the stoma due to leakage of cervical esophageal anastomosis served further, additionally to the above functions, to separate the anastomotic leakage area till its closure. The patient received regular dressings and leakage area management using antiseptic solutions. The anastomotic leakage area closed on the 10th day after its appearance. 3 $(5,7 \%)$ comparison group patients had a partial leakage of cervical esophageal anastomosis which required to continue maintaining the nasogastric tube in order to "strengthen" the anastomosis area, separate the anastomotic leakage area and continue enteral feeding. Those patients received regular dressings and leakage area management using antiseptic solutions. The anastomotic leakage area closed on the 12-14th day after its appearance. Necrosis of the proximal large intestinal interponate with the total leakage of cervical esophageal anastomosis were observed in $2(3,8 \%)$ comparison group patients after esophagocoloplasty at Step II of the surgical treatment. These patients were apt to active surgical tactics with relaparotomy and additional cervical access, extirpation of the colointerponate with subsequent formation of esophagostoma for saliva discharge at the left side of the neck and of gastrostomy for enteral feeding. One patient was discharged from the hospital on the 17th day after relaparotomy and returned after 6,5 months for the reconstructive surgery. Another patient was died on the third day after relaparotomy due to multiple organ failure. Partial leakage of thoracic esophageal anastomosis was in $1(1,9 \%)$ patient of the comparison group and resulted later in mediastinitis and multiple organ failure. This patient died. One comparison group patient on the 5 th day after esophagocoloplasty had a partial leakage of intraabdominal colo-coloanastomosis which caused peritonitis. The patient underwent relaparotomy, resection of anastomosis area to form a new anastomosis, thorough abdominal cavity lavage, and Petrov draining, intestine intubation.

Post-operation lethality in the main group - 1 person $(2,0 \%)$ of 49 patients, whereas in the comparison group - 2 persons $(3,8 \%)$ of 53 patients.

Assessment of patients' life quality and their treatment efficiency consisted in the evaluation of gastroenterological patients' treatment efficiency at the different time periods of treatment by objective and subjective parameters and their integral estimation. Assessment at the hospitalization evidenced the lower life quality in the main group patients. At the early postsurgical period on the 10th day after esophagoplasty and later on the 20th and 30th day, all objective and subjective life quality parameters confirmed a higher treatment efficiency and better life quality in the main group patients. Lower life quality parameters in the comparison group patients were caused by a higher amount of postsurgical complications and higher postsurgical lethality.

There were absent complaints more than 1 month after surgery in $44(89,8 \%)$ patients of the main group and 37 $(69,8 \%)$ patients of the comparison group. It evidences of better efficiency of the performed treatment in the main group. Long-term complications in patients after esophagoplasty were observed in $18(17,6 \%)$ patients (Table 2).

The analysis of the long-term treatment results of extended post-burn esophageal cicatricial stricture patients after esophagoplasty found the substantially lower frequency of complications in the main group of patients. Moreover, complications due to the surgery in the main group were easily corrected by conservative and mini-invasive methods, whereas $2(3,8 \%)$ patients of the comparison group they required reconstructive surgery. This is an evidence of substantially better long-term results of the surgical treatment in the main group.

Within the subsequent period after esophagoplasty in $1,3,6,9,12$ months all life quality parameters reflected a better life of the main group patients $(\mathrm{p}<0,05)$ relative to the comparison group.

\section{CONCLUSIONS}

Our research proved that in patients with extended postburn esophageal cicatricial strictures application of the proposed surgical tactics, modified method of single-step esophagoplasty and esophagoplasty as Step II of the surgical treatment for persons who have a formed contact gastrostomy with transhiatal resection of esophagus, exteriorization of interponate on the neck as a contact stoma and "endto-side" anastomosis formation on the neck between the esophageal stump and interponate is an efficient means for patients' treatment improvement.

\section{REFERENCES}

1. Zherlov GK, Zykov AV, Plotnikov EV et al. Multistage treatment of esophagus and stomach high severity total burn. Khirurgiya. 2006;12:41-42. (In Russian).

2. Kochhar R, Sethy PK, Kochhar S et al. Corrosive induced carcinoma of esophagus: report of three patients and review of literature. Journal of Gastroenterology and Hepatology. 2006;21: 777-780.

3. Khadjibayev AM. Endoscopic diagnostics and treatment of chemical burns of esophagus. Khirurgiya Uzbekistana. 2007;3:46. (In Russian).

4. Fulton JA, Hoffman RS. Steroids in second degree caustic burns of the esophagus: a systematic pooled analysis of fifty years of human data: 1956-2006. Clinical Toxicology. 2007;45: 402-408.

5. Kasnoselskiy NV, Krivoruchko IA, Shalkov YuL et al. Savinykh's esophageal resection according with restoration of digestive pipe integrity by a gastrotransplantate. Klinichna onkologiya. 2011;2:10. (In Russian). 
6. BoykoVV, Savvi SO, Bodrova AYu et al. Two-Step surgical treatment of post-burn esophagus cicatricial stricture. Klinichna khirurgiia: zbirnyk naukovykh robitXXIII ziizdu khirurgiv Ukrainy, 21-23 October 2015, Kyiv. 2015:49-50. (In Ukrainian).

7. Parshin VD, Chernousov FA, Vishnevskaya GA et al. Single-Step treatment of extended windpipe and esophagus stenoses. Grudnaya i serdechnososudistaya khirurgiya. 2010;3:69-73. (In Russian).

8. Boyko VV, Savvi SO, Ivanova YuV et al. Reconstructive reparative surgeries in extended post-burn cicatricial esophageal stricture patients. Kharkivska khirurgichna shkola. 2016;3:139-145. (In Russian).

9. Singhal S, Hasan SS, Cohen DC et al. Multi-disciplinary approach for management of refractory benign occlusive esophageal strictures. Therapeutic advances in gastroenterology. 2013;6(5): 365-370.

10. Boyko VV, Savvi SO, Korolevska AYu et al. Analysis of long-term treatment results in extended post-burn cicatricial esophageal stricture patients after esophagocoloplasty. Khirurgiiia Ukrainy. 2018;4:12-13. (In Ukrainian).

The research is performed according to the scientific subject of the State Institution "Zaitsev V. T. Institute of General and Urgent Surgery of National Academy of Medical Sciences of Ukraine". It is a fragment of researches "To develop the surgical tactics in patients with extended post-burn cicatricial esophageal strictures using transchiatal esophagoplasty" [State registration № 0114U000084] and "To develop transchiatal reconstructive surgeries in patients with leackage of esophageal anastomoses, esophageal injures and perforations" [State registration № 0117U000341].

\section{ORCID and contributionship:}

Valeriy V. Boyko - 0000-0002-3455-9705 A,F

Serhii O. Savvi - 0000-0002-3636-5875 A,E,F

Alla Yu. Korolevska - 0000-0003-2903-205X A,C,D

Serhii Yu. Bytyak - 0000-0002-6012-2048 ${ }^{B, C, E}$

Vitalii V. Zhydetskyi - 0000-0001-7873-6366 ${ }^{B, C}$

Yevhen A. Novikov - 0000-0002-5039-5114 D,E,F

Robert O. Surmanidze - 0000-0001-5274-7518 ${ }^{E}$

\section{Conflicts of interest:}

Authors declare no conflict of interest.

\section{CORRESPONDING AUTHOR}

Alla Yu. Korolevska

SI "Zaitsev V.T. IGUS of NAMSU"

Balakireva vjizd, 1, 61103, Kharkiv, Ukraine

tel: +380673793118

e-mail:korolevska@ukr.net

Received: 08.09 .2019

Accepted: 29.11.2019

A - Work concept and design, B - Data collection and analysis, C - Responsibility for statistical analysis, D-Writing the article, $\mathbf{E}$-Critical review, $\mathbf{F}$ - Final approval of the article 